\title{
Equipment
}

\section{An evaluation of the N-CAT, a new arterial tonometer}

Norman R. Searle MD, Jean Gauthier MD, Philippe Sahab MD
The $N-C A T$ is a newly developed arterial tonometer (TBP) monitor able to determine systolic, diastolic and mean blood pressures continuously and noninvasively. The aim of this study was to evaluate the accuracy and reliability of the TBP compared with directly measured invasive blood pressure (IBP) in 14 patients before and after elective coronary artery bypass surgery. Although the TBP was able to track changes in systemic pressure, before and after CPB, bias and precision for $T B P$ monitoring did not meet the standard criteria for equivalency for noninvasive blood pressure to invasive blood pressure. We were unable to monitor TBP in two patients. Approximately $40 \%$ of all before and afier CPB mean TBP pressure values differed from mean IBP by more than 10 $\mathrm{mmHg}$. Moreover, there were discrepancies of sufficient magnitude and duration that limits the clinical usefulness of the $N-C A T$. Potential users should not rely exclusively on TBP values when making clinical decisions. Technological improvement is needed before its clinical use is recommended.

Le $N$-CAT est un nouveau moniteur de pression artérielle qui utilise le principe de la tonométrie artérielle (TBP) pour déterminer la pression systolique, diastolique, et moyenne de façon continue et non invasive. Le but de cette étude est d'évaluer la précision et la fiabilité de la TBP par rapport à la pression artérielle invasive (IBP) chez des patients avant une chirurgie cardiaque (pré-CEC) et après chirurgie cardiaque (post-CEC). La TBP a été capable de détecter les changements de pression. Cependant, les valeurs de biais et de précision pré- et postCEC n'ont pas rencontré les critères de l'Association for the

\section{Key words}

MEASUREMENT TECHNIQUES: blood pressure; HEART: coronary artery bypass.

From the Department of Anesthesia, Montreal Heart Institute, 5000 Belanger Street, Montreal, Quebec, H1T 1C8 Canada.

Presented in part at the Annual Meeting of the American Society of Anesthesiologists, New Orleans, LA, 1992. Address correspondence to: Dr. Norman R. Searle, Department of Anesthesia, Montreal Heart Institute. Accepted for publication 10th February, 1995.
Advancement of Medical Instrumentation. Nous avons éga lement été incapables de monitorer la TBP chez deux patients. Environ 40,3\% des différences entre la TBP et l'TBP moyenne se situaient dans lintervalle supérieur à $10 \mathrm{mmHg}$ pré-CEC et $41,2 \%$ post-CEC. De plus, il y a eu des moments où la différence entre la TBP et l'IBP était de durée et de magnitude non acceptables, limitant son utilité chez des patients où la mesure exacte et continue de la pression artérielle est souhaitable. Des améliorations technologiques seraient souhaitables avant que son utilisation clinique soit recommandée.

The frequent measurement of blood pressure during anaesthesia is important and is considered standard practice for good clinical care. Continuous invasive blood pressure (IBP) measurement is usually indicated when accurate measurements are required during low-pressure states (controlled hypotension) or if rapid changes in blood pressure are anticipated. However, in those patients in whom there are no absolute indications for invasive arterial pressure, an accurate noninvasive and continuous blood pressure monitor would be preferable to IBP. Radial arterial tonometry (TBP) has been introduced to provide continuous, noninvasive measurement of blood pressure. The goal of this technology is to offer the clinician the opportunity to detect changes in blood pressure more rapidly than by intermittent oscillometric measurements alone. One such apparatus is the N-CAT N-500 (Nellcor, Hayward, CA) monitor which relies on TBP for generating the blood pressure wave form. ${ }^{1}$ The principle of arterial tonometry relies on a series of piezoresistive pressure transducers that are able to sense radial artery pulse signal and generate an arterial wave form. ${ }^{2}$ The N-CAT has an integrated blood pressure device that calibrates the piezoresistive transducers intermittently, using the oscillometric technique.

Previous reports have provided some information about the performance of TBP in the clinical setting. ${ }^{2,3}$ Investigations are needed to evaluate these monitors under various pathological states and different patient morphological characteristics. The purpose of this study 
was to examine the accuracy of the TBP before and after cardiopulmonary bypass surgery which may cause increased soft tissue oedema. ${ }^{4}$ Understanding the limitations may guide future improvement of the device and help delineate the appropriate place of TBP in patient monitoring.

\section{Methods}

After approval from our Bioethics Committee, 14 patients were studied. All were undergoing elective coronary artery bypass surgery (CABG). Excluded from study were patients who had different noninvasive blood pressure values $(>10 \mathrm{mmHg}$ ) on the left and right sides. All patients had IBP after a 20-g Teflon cannula was inserted in a radial artery as part of their routine monitoring. The IBP consisted of a disposable high-fidelity pressure transducer (Sorensen Transpac, Abbott Critical Care System, Chicago, Ill.) The arterial cannula was connected to the pressure transducer with a $180 \mathrm{~cm}$ long, $1.5 \mathrm{~mm}$ internal diameter, low compliance tubing. The arterial transducer was zeroed at the mid-axillary line and calibration was checked for accuracy and linearity with a mercury manometer following internal electrical calibration. The characteristic of the dynamic response of the IBP system was not measured, but using the fast flush technique, no excessive damping or ringing was noticed. ${ }^{5-7}$ The transducer wave form was displayed on a Siemens 1281 monitor (Siemens Critical Electronics Inc., Danvers, MA) and the cable attachment was verified with a Sorensen Transpac Transducer Simulator (No 4260101 Abbott Critical Care System, Chicago, Ill).

The contralateral radial artery was used to determine TBP. The wrist-mounted apparatus was apposed to the radial artery and the arterial waveform was reproduced on the N-CAT N-500 monitor. Calibration for TBP was obtained from oscillometric blood pressure determinations using a blood pressure cuff of appropriate size. Oscillometric blood pressure was determined on the ipsilateral side to the IBP. This calibration was performed every two and half minutes for three consecutive measurements and then automatically at five-minute intervals. The calibration period was excluded from the data analysis.

Each patient served as their own control and was studied for $50 \mathrm{~min}$ pre-CPB and for a similar period one hour after arrival in the Intensive Care Unit. Before and after surgery, wrist circumference $(\mathrm{cm})$ was measured at the same level as the tonometric blood pressure sensor to assess local soft tissue oedema. Also, we continuously recorded the hold-down pressure (HDP) which represents the pressure exerted by a pneumatic pump and bellows over the transducer array against the skin and tissue above the radial artery, and the signal strength (SS), an arbitrary internal numeric display from the N-CAT monitor during these two periods. For the purpose of the study, each 60 -sec average signal was considered a onetime sample for comparison of TBP and IBP measurements. Paired values for systolic, diastolic and mean pressures were compared by Student's $t$ test for difference between the two blood pressure methods. Also, the accuracy of the N-CAT monitor was determined by measuring its bias (i.e., tendency to overestimate or underestimate) and precision (i.e., mean absolute error) according to the following formulas

Bias $=\sum_{i=1}^{n} \frac{\text { TBP-IBP }}{n} \quad$ Precision $=\sum_{i=1}^{n} \frac{\mid \text { TBP-IBP } \mid}{n}$

where $i=$ pressure determination and $n=$ number of pressures compared. ${ }^{2}$ Individual pre- and post-CPB bias and precision for systemic pressures were averaged to give the average bias and precision for the N-CAT monitor. Thus, each patient contributed equally to the measurement of the performance of this device. Statistical significance was established when $P<0.05$.

Scatterplots of paired TBP-IBP differences versus the average of the paired blood pressure measurements for systolic, diastolic, and mean pressures were made according to the method of Bland and Altman. ${ }^{8}$

Lastly, we calculated the occurrence of two or more consecutive paired measurements during which the difference between TBP and IBP was either $>10 \mathrm{mmHg}$ or $>20 \mathrm{mmHg}$. These were then expressed as discrepancies per patient-hour for an interval of one to five minutes or more than five minutes. ${ }^{9}$ These frequencies were averaged for the 14 patients studied.

\section{Results}

Complete measurements were obtained from ten men and one woman before and after CPB. In two patients, complete measurements could not be obtained due to TBP failure in detecting a pulse pressure in the pre-CPB period (one subject) and in the post-CPB (one subject). A third subject died intraoperatively. These patients' data were excluded from the final analysis. Their average age, weight and height were $57.1 \pm 8.9 \mathrm{yr}, 89.4 \pm 17.8 \mathrm{~kg}$, and $166.2 \pm 8.6 \mathrm{~cm}$, respectively. A total of 550 pairs of pre- and post-CPB systolic, diastolic and mean TBP and IBP were analyzed.

There was an increase in wrist circumference post-CPB $(17.2 \pm 1.5 \mathrm{~cm}$ vs $17.9 \pm 1.6 \mathrm{~cm}, P<0.001)$ and HDP $(84 \pm 17.2 \mathrm{mmHg}$ vs $118 \pm 21.9 \mathrm{mmHg}, P<0.001)$ while SS decreased (118.6 \pm 46 vs $73.2 \pm 33.2, P<$ $0.001)$.

Tonometric blood pressure was able to track changes in systemic blood pressure. Single minute averages pre- 

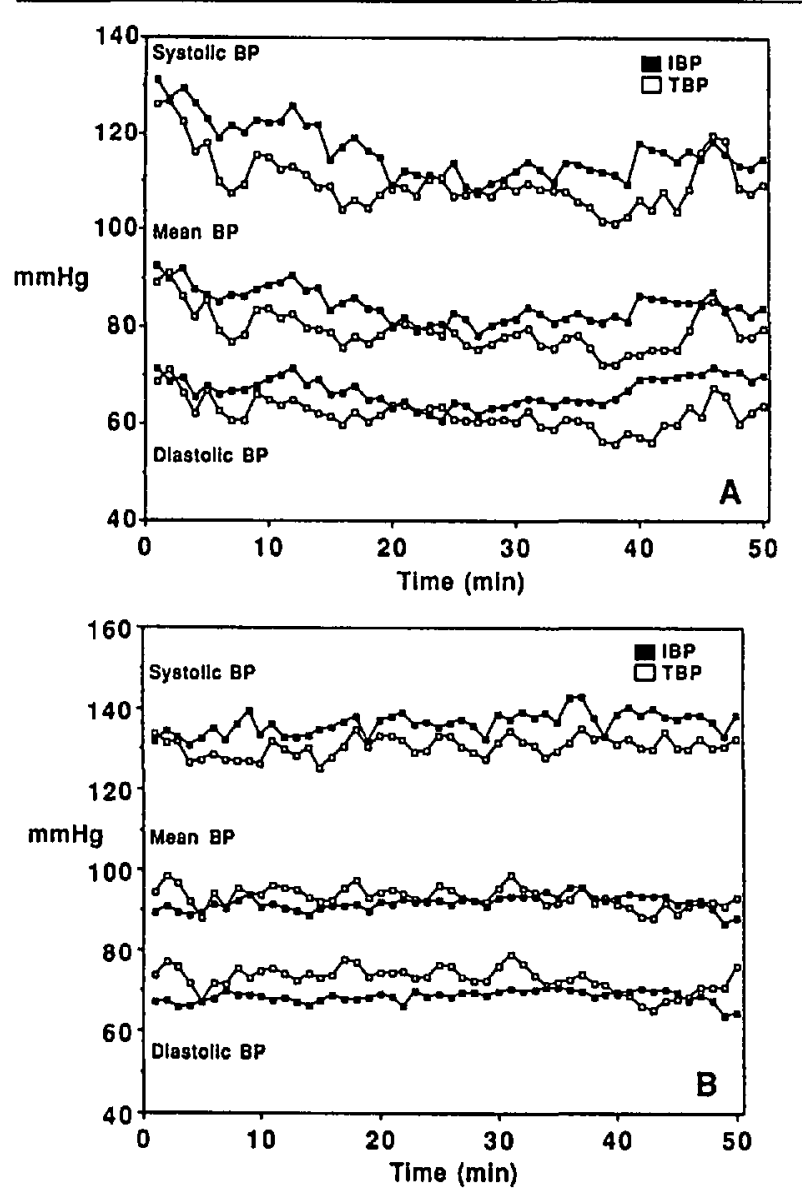

FIGURE 1 Graphic representation of single minute average for systolic, diastolic and mean tonometric blood pressure (TBP) and invasive blood pressure (IBP). (A) Pre-cardiopulmonary bypass and (B) post-cardiopulmonary bypass.

and post-CPB for TBP and IBP are plotted in Figures $1 A$ and $1 B$. During the pre-CPB period, all IBP values remained consistently higher than TBP values (Figure 1A) while for the post-CPB period, only the systolic IBP values remained higher than the TBP reading (Figure 1B). Individual and group bias and precision values preand post-CPB are listed in Tables I and II.

Because of similar distribution for systolic and diastolic TBP and IBP pressure differences, only the mean blood pressure values are presented. Scatterplots and histograms of the pre- and post-CPB mean TBP and IBP pressure differences are shown in Figures 2 and 3, respectively. Approximately $40 \%$ of the mean TBP reading differed by $>10 \mathrm{mmHg}$ (Figure 3). Interestingly, the distribution differed between the two periods. During the pre-CPB period, mean TBP tended to underestimate mean IBP by $>10 \mathrm{mmHg}$ in $30 \%$ of the measurements while in the post-CPB period, it tended to occur in only $15 \%$ of the measurements.

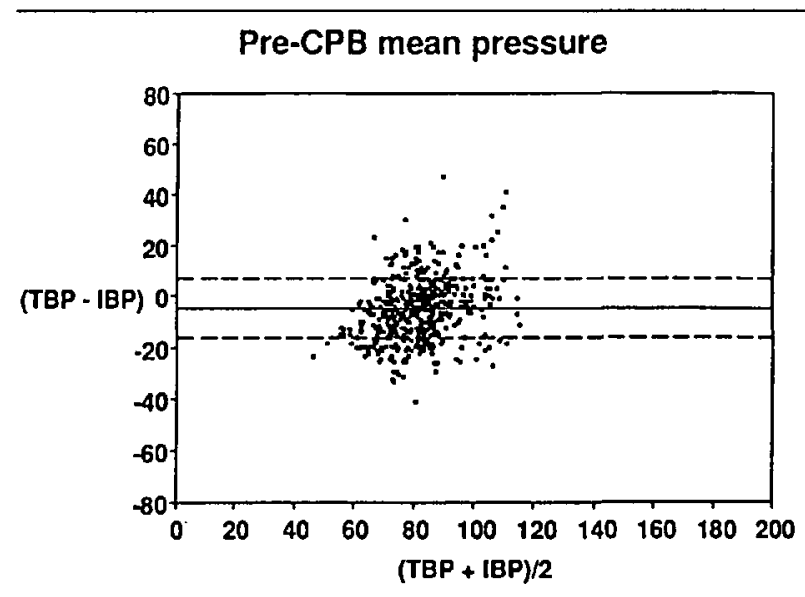

Post-CPB mean pressure

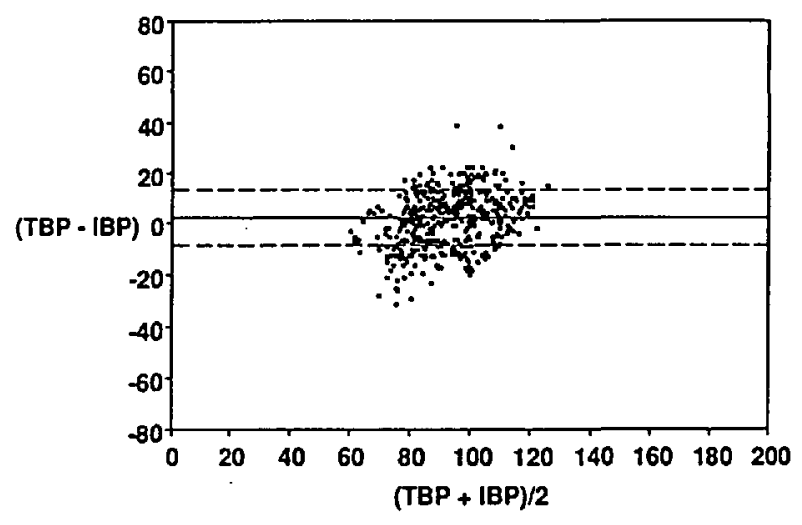

FIGURE 2 Scatterplots of the difference between mean tonometric blood pressure (TBP) and invasive blood pressure (IBP) versus the average mean TBP and IBP values. The average bias line is marked by the solid line. The 2 SD limits of the bias are given by the dotted lines. The upper plot relates to the pre-cardiopulmonary bypass while the lower plot relates to the post-cardiopulmonary bypass.

The duration and magnitude of blood pressure differences, expressed as discrepancies per patient-hour are plotted in Figure 4. In this histogram, discrepancies of <one minute and/or $<10 \mathrm{mmHg}$ of blood pressure differences are not indicated. Discrepancies of $10-20 \mathrm{mmHg}$ and $>20 \mathrm{mmHg}$ are indicated for the intervals of one to five minutes and $>$ five minutes. The greatest number of discrepancies occurred in the $10-20 \mathrm{mmHg}$ and for the interval of one to five minutes. There was no difference in the discrepancy values obtained before and after CPB.

\section{Discussion}

For a non-IBP device to be considered equivalent to IBP measurements, the average bias should be within \pm 5 $\mathrm{mmHg}$ and the standard deviation of the bias $\leq 8 \mathrm{mmHg}$ (Association for the Advancement of the Medical Instru- 
TABLE I Tonometric blood pressure bias and precision values pre-cardiopulmonary bypass

\begin{tabular}{lrrrrrr}
\hline Patients & $\begin{array}{l}\text { Syst } \\
\text { bias }\end{array}$ & $\begin{array}{l}\text { Diast } \\
\text { bias }\end{array}$ & $\begin{array}{l}\text { Mean } \\
\text { bias }\end{array}$ & $\begin{array}{l}\text { Syst } \\
\text { prec }\end{array}$ & $\begin{array}{l}\text { Diast } \\
\text { prec }\end{array}$ & $\begin{array}{l}\text { Mean } \\
\text { prec }\end{array}$ \\
\hline 1 & -7.62 & 1.42 & -1.98 & 12.31 & 6.47 & 7.95 \\
2 & -5.83 & -11.48 & -9.71 & 9.86 & 11.94 & 10.02 \\
3 & 1.65 & 0.89 & -0.93 & 7.74 & 4.67 & 6.15 \\
4 & -3.00 & -8.22 & -7.82 & 5.59 & 8.49 & 7.90 \\
5 & 0.15 & -6.30 & -3.37 & 10.03 & 9.34 & 7.67 \\
6 & 2.11 & 6.17 & 4.83 & 8.86 & 7.09 & 7.23 \\
7 & -11.50 & -16.60 & -14.62 & 12.82 & 16.88 & 14.86 \\
8 & -6.92 & 3.89 & 0.24 & 12.35 & 9.30 & 7.92 \\
9 & 2.17 & 7.78 & 4.58 & 11.00 & 9.72 & 8.58 \\
10 & -13.28 & -5.32 & -7.14 & 17.67 & 10.68 & 11.04 \\
11 & -16.54 & -11.17 & -9.46 & 22.31 & 14.71 & 14.85 \\
Mean & -5.33 & -3.54 & -4.13 & 11.87 & 9.94 & 9.47 \\
SD & 6.56 & 8.04 & 6.19 & 4.67 & 3.55 & 2.97 \\
\hline
\end{tabular}

Diast $=$ diastolic $;$ Prec $=$ precision $;$ Syst $=$ systolic

TABLE II Tonometric blood pressure bias and precision values post-cardiopulmonary bypass

\begin{tabular}{lrrrrrr}
\hline Patients & $\begin{array}{l}\text { Syst } \\
\text { bias }\end{array}$ & $\begin{array}{l}\text { Diast } \\
\text { bias }\end{array}$ & $\begin{array}{l}\text { Mean } \\
\text { bias }\end{array}$ & $\begin{array}{l}\text { Syst } \\
\text { prec }\end{array}$ & $\begin{array}{l}\text { Diast } \\
\text { prec }\end{array}$ & $\begin{array}{l}\text { Mean } \\
\text { prec }\end{array}$ \\
\hline 1 & -13.20 & 4.70 & -2.84 & 16.64 & 9.58 & 9.76 \\
2 & 2.04 & 13.51 & 12.86 & 6.08 & 13.51 & 12.86 \\
3 & -18.25 & -3.83 & -12.15 & 18.42 & 4.46 & 12.15 \\
4 & -12.38 & 16.68 & 9.77 & 14.02 & 17.11 & 10.38 \\
5 & 13.89 & 6.02 & 9.04 & 16.73 & 11.71 & 13.31 \\
6 & -3.51 & 1.62 & -0.40 & 10.83 & 9.53 & 7.81 \\
7 & -15.75 & 4.38 & -1.69 & 17.33 & 6.58 & 6.38 \\
8 & -2.11 & 5.49 & 3.91 & 9.81 & 7.94 & 6.47 \\
9 & -4.84 & 3.96 & -0.36 & 11.53 & 8.95 & 8.11 \\
10 & 4.88 & -1.30 & 4.32 & 9.04 & 7.42 & 7.40 \\
11 & -15.80 & -3.27 & -5.96 & 16.65 & 5.96 & 6.61 \\
Mean & -5.91 & 4.36 & 1.50 & 13.37 & 9.34 & 9.20 \\
SD & 10.17 & 6.36 & 7.39 & 4.11 & 3.63 & 2.63 \\
\hline
\end{tabular}

Diast $=$ diastolic $;$ Prec $=$ precision $;$ Syst $=$ systolic

mentation SP10: 1-25, 1987). Pre- and post-CPB average systolic TBP bias values $(-5.33 \pm 5.56$ and $-5.91 \pm$ $10.17 \mathrm{mmHg}$, respectively) fell outside these criteria while the average diastolic $(-3.54 \pm 8.04$ and $4.36 \pm 6.36$ $\mathrm{mmHg}$, respectively) and mean $(-4.13 \pm 6.19$ and 1.50 $\pm 7.39 \mathrm{mmHg}$, respectively) TBP bias values were acceptable. Our current bias results differ from our previous report $^{2}$ and from those of Kemmotsu et al. ${ }^{3,10}$ A disturbing finding (Tables I and II) was that certain individual bias values were within the acceptable criteria for equivalency during the pre-CPB period while during the post-CPB period, the values fell outside the norms and the reverse was also true. Potential for greater bias may be related to physiological differences between the two arms when comparing IBP with TBP measurements from the contralateral arm. We cannot rule out this possibility in our study population, but none of our patients had oscillometric blood pressure differences $>10 \mathrm{mmHg}$. The average precision values for all TBP measurements were unacceptably high. Furthermore, we were unable to monitor TBP consistently in two patients (one pre-CPB and one post-CPB).

It is difficult to state what magnitude and duration of error in blood pressure measurement is clinically important. Miost anaesthetists would agree that discrepancies of only a few $\mathrm{mmHg}$ are of little clinical significance. However, we would be concerned if the range of error was $>10 \mathrm{mmHg}$ and of a duration of more than one minute. During the pre-CPB period, we considered it unacceptable that patients averaged 3.8 and 0.9 discrepancies per patient-hour of $>10-20 \mathrm{mmHg}$ and $>20$ $\mathrm{mmHg}$ respectively lasting one to five minutes (Figure 4). These values are higher than those reported for a similar patient population with atrial fibrillation. ${ }^{2}$ If the 

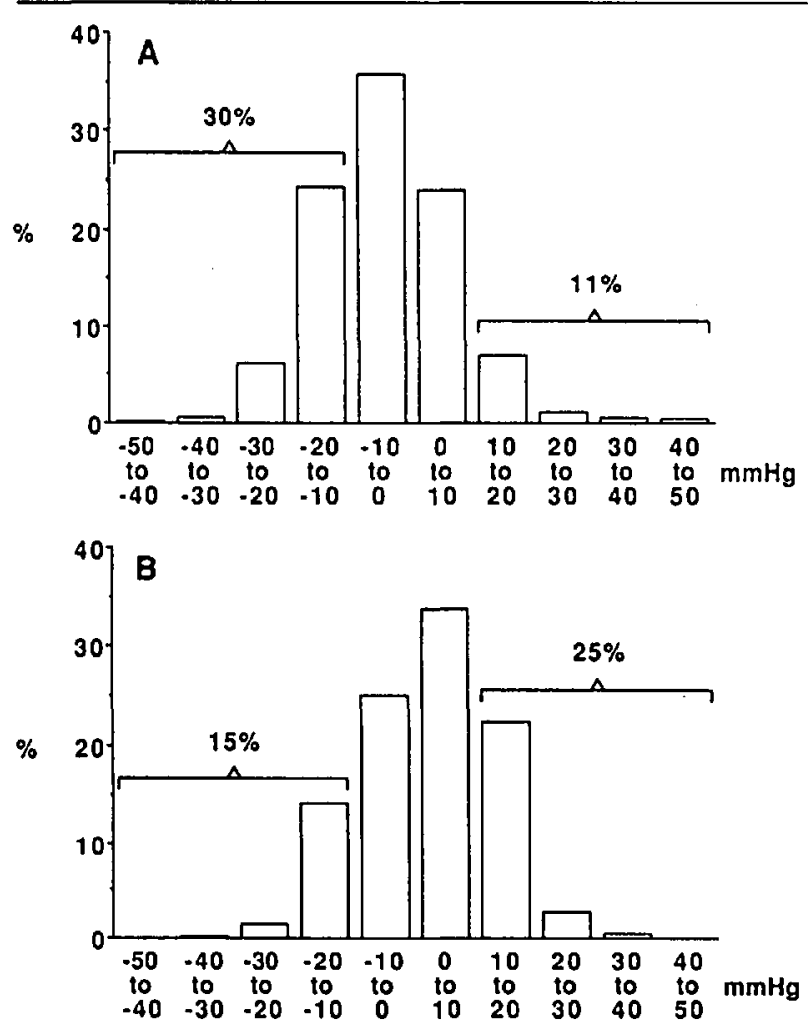

FIGURE 3 Histograms representing the frequency distribution for the difference between mean tonometric blood pressure (TBP) and invasive blood pressure (IBP). The percentage values indicate the number of reading that differed by $>10 \mathrm{mmHg}$. (A) Precardiopulmonary bypass and (B) post-cardiopulmonary bypass.

upper limit of $\pm 10 \mathrm{mmHg}$ is accepted, then approximately $41 \%$ of all mean TBP values before and after CPB differed from IBP by more than $>10 \mathrm{mmHg}$ (Figures $3 \mathrm{~A}$ and $3 \mathrm{~B}$ ). These percentage values are nearly twice that reported in previous studies. ${ }^{2,11}$

During general anaesthesia as during other forms of anaesthesia, inaccurate TBP values might lead the clinician to undertake a therapeutic intervention that is unnecessary, not indicated and harmful to the patient. We should be concerned that this situation may increase morbidity in such patients. Potential users should not rely exclusively on TBP reading for making therapeutic decisions. Given the design of our experimental protocol and the lack of: (1) any study with of TBP with which ours can be compared, and (2) appropriate statistical analysis for data of this type, our results suggest that TBP should not be substituted for invasive arterial measurements. To enhance the performance of TBP, efforts could be directed toward improving the piezoelectric crystal array and improving the method of calibration. Recently, Seigel et al. have demonstrated that the oscillometric calibration is the largest source of errors and that

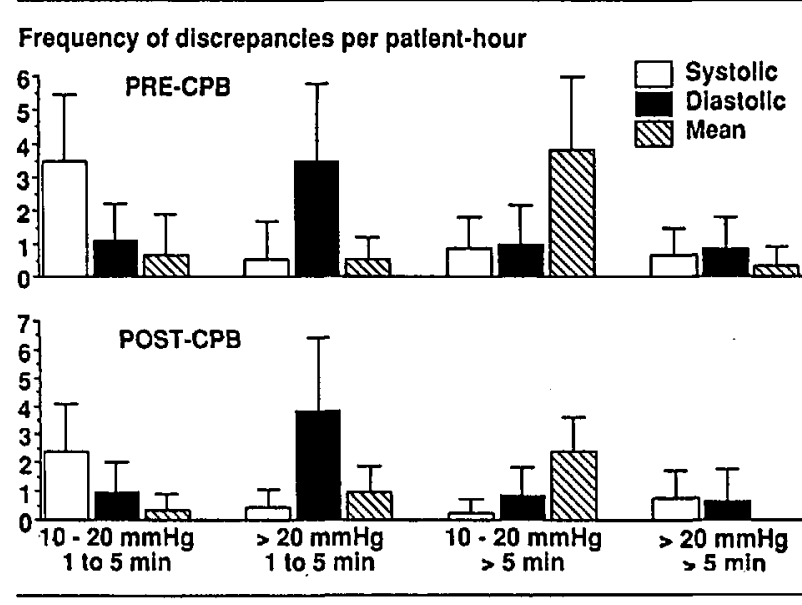

FIGURE 4 The duration of discrepancies per patient-hour between systolic, diastolic and mean tonometric blood pressure (TBP) and invasive blood pressure (IBP). The histograms indicate mean \pm SD. The upper panel indicates pre-cardiopulmonary bypass while the lower panel indicates post-cardiopulmonary bypass.

it may prove difficult to improve on its performance. " Development of smaller transducers for more precise positioning may avoid failure in some patients.

\section{Study limitations}

Inherent in the study design are the changes in pulse pressure wave contour that occur during propagation of the pressure wave from central to peripheral vessels. ${ }^{12}$ This may cause differences between oscillometric (brachial) and distal arterial (radial) pressures. Such differences may be exaggerated by the dynamic changes in arterial elastance caused by the hypothermic $\mathrm{CPB},{ }^{13}$ vasoactive drugs, and limitation of the electronic IBP system. ${ }^{7}$ Furthermore, we recognize that the interval of calibration, the use of the contralateral arm for TBP measurement, the use of a 60 -sec average rather than a beat-to-beat comparison and the small number of a select patient population may modify our conclusions. Until further clinical evaluation and techological improvement come forth, we do not recommend its use for beat-to-beat blood pressure monitoring.

\section{References}

1 Drzewiecki GM, Melbin J, Noordergraaf $A$. Arterial tonometry: review and analysis. J Biomech 1983; 16: 141-52.

2 Searle NR, Perrault J, Ste-Marie H, Dupont C.

Assessment of the arterial tonometer (N-CAT) for the continuous blood pressure measurement in rapid atrial fibrillation. Can J Anaesth 1993; 40: 388-93.

3 Kemmotsu $O$, Ueda $M$, Otsuka $H$, et al. Blood pressure measurement by arterial tonometry in controlled hypotension. Anesth Analg 1991; 73: 54-8.

4 Smith EEJ, Naftel DC, Blackstone EH, Kirklin JW. 
Microvascular permeability after cardiopulmonary bypass.

An experimental study. J Thorac Cardiovasc Surg 1987; 94 : 225-33.

5 Quill TJ. Blood pressure monitoring. In: Ehrenwerth J, Eisenkraft JB (Eds.). Anesthesia Equipment: Principles and Applications. St. Louis: Mosby, 1993; 274-83.

6 Gardner RM. Direct blood pressure measurement dynamic response requirements. Anesthesiology 1981; 54: 227-36.

7 Hunziker $P$. Accuracy and dynamic response of disposable pressure transducer-tubing systems. Can J Anaesth 1987; 34: 409-14.

8 Bland JM, Altman DG. Statistical methods for assessing agreement between two methods of clinical measurement. Lancet 1986; 1: 307-10.

9 Gibbs NM, Larach DR, Derr JA. The accuracy of Finapres(Ti) noninvasive mean arterial pressure measurements in anesthetized patients. Anesthesiology 1991; 74: 647-52.

10 Kemmotsu O, Ueda M, Otsuka H, Yamamura $T$, Winter $D C$, Eckerle JS. Arterial tonometry for noninvasive, continuous blood pressure monitoring during anesthesia. Anesthesiology 1991; 75: 333-40.

11 Siegel LC, Brock-Utne JG, Brodsky JB. Comparison of arterial tonometry with radial artery catheter measurements of blood pressure in anesthetized patients. Anesthesiology 1994; 81: 578-84.

12 Bruner JMR, Krenis LJ, Kunsman JM, Sherman AP. Comparison of direct and indirect methods of measuring arterial blood pressure. Medical Instrumentation 1981; 15: 11-21.

13 Stern DH, Gerson JI, Allen FB, Parker FB. Can we trust the direct radial artery pressure immediately following cardiopulmonary bypass? Anesthesiology 1985; 62: 557-61. 